\title{
CLIMATIC FACTOR IN LONG-TERM DEVELOPMENT OF FOREST ECOSYSTEMS
}

\author{
Prof. Dr. Fedor LISETSKII ${ }^{1}$, Assoc. Prof. PhD. Marina POLSHINA ${ }^{1}$ \\ Assoc. Prof. PhD. Vitalii PICHURA ${ }^{2}$ \\ PhD. Olga MARININA ${ }^{1}$
}

${ }^{1}$ Belgorod State National Research University, Depth of Environmental Management and Land
Survey, 308015 Belgorod - Russian Federation
${ }^{2}$ Kherson State Agricultural University, Department of fisheries and nature use, 73006 Kherson
- Ukraine ABSTRACT

Rhythmic climate changes determine the necessity to refer to long time series to detect low-frequency vibrations of climatic parameters and their influence on the growth processes in ecosystems. Dendrochronological research of pubescent oak (Quercus pubescens Willd) in forest communities of the foothill forest-steppe (250-350 $\mathrm{m}$ a.s.1.) and core samples of buried wood in comparison with modern and reconstructed climatic conditions was carried out. The purpose of work was to develop regional tree-ring chronologies for modern and ancient periods, to establish the connection of radial growth (including indices related to early and late wood) with climatic indicators and reconstruction of ancient climate based on dendrochronological data using new methods of time series processing. Radial growths of fossil oak wood from mound of ancient times which were used to build 40 years long tree-ring chronology were compared with the growths of core samples of modern oak trees of the nearby forests (12 sites). Using basic meteorological heat and moisture data (1887-2016) as well as the results of their conversion into energy equivalents sustainable bioclimatic periods were established, and using mathematical model chrono-organization of regional climatic system was defined. Statistical analysis of the growth indices (total, those of early and late wood) detected no significant differences in the average growths as related to ancient and modern times. Using a complex of statistical methods climatic parameters reconstructions and chronoorganizations of half-century changes in forest site in ancient times were performed.

Keywords: foothill oaks, dendrochronology, ancient epoch, the climate reconstruction.

\section{INTRODUCTION}

The area of the modern oak forests in the European part of Russia for the last 2-2.5 ka years has decreased by an average of 7 times, with the initial afforestation of $24.5 \%$ [1]. In this connection, the study of long-lived trees is of great informational importance. On 
the piedmont forest-steppe, isolated forest tracts, as the remains of the larger forests of the past, are in extreme environmental conditions and therefore are sensitive to climate change. Trees that are highly sensitive to temperature (including Pinus) may enhance the long-term climate signal for performing reliable climate reconstructions because they reduce potential biases derived from non-climatic influences on tree growth [2]. Treering-based reconstruction of temperature variability with the help of spectral analyses suggested that the reconstructed annual mean temperature variation may be related to large-scale atmospheric-oceanic variability such as the solar activity [3].

The combination of living trees and relic material is an important paleoecological archive, which allows construction of continuous chronologies with a duration from some centuries to millennia [4]. The morphology and properties of buried soils can reflect long climatic periods. In the steppe zone of the Eastern Europe, the tradition of erecting mound structures (kurgans) has been kept for thousands of years and therefore the buried soils can be up to 4500 years old [5]. The short time intervals in the course of which there were changes in the sign of the soil formation index from positive to negative may characterize epochs of ecological crises [6].

\section{DATA AND METHODS}

Description of the study area. The piedmont forest-steppe climate with a warm dry summer and an unstable winter is a transitional one from the steppe to the mountain forest climate. The annual air temperature $(\mathrm{t})$ is $10.6 \pm 0.1^{\circ} \mathrm{C}\left(8.3 \div 13^{\circ}\right)$; average $\mathrm{t}(\mathrm{I})$ is $0.2^{\circ} \mathrm{C}, \mathrm{t}$ (VII) is $+22.5^{\circ} \mathrm{C}$. The frost-free period lasts for 312 days. The amount of precipitation in the centre piedmont (station Belogorsk) is $482(354 \div 775) \mathrm{mm}$. Background soils in the study area is Lithic Leptosols on the eluvia of parent limestone in complex with Calcic Chernozems gravelly. Apparently, in this piedmont zone, the impermeable bedrocks lie near the surface, although there are no usual signs of salinization [7]. In the Belogorsk region on an area of upland (altitude of $320 \mathrm{~m}$ a.s.l.) there is the kurgan "Ak-Kaya 9", 9.5 $\mathrm{m}$ high, which has been excavated. In Crimea, the forest areas and standing forest, which are not part of the forest resources, occupy $11.5 \%$ of the total area. Where the portion of oak forests is $66.5 \%$ of the whole forest-covered area. However, the area of the mature and over mature oak (101 years and more) stands does not exceed 10\%. Forests are more significantly represented in the area of our study. The portion of forests and other wooded areas is $29.4 \%$ of the total area of the Belogorsk region (189 356 ha). In terms of the terrain, this territory represents a piedmont forest-steppe. At present, the main forestforming species in the isolated forest tracts are oaks: pubescent (Quercus pubescens), rocky ( $Q$. petraea), crooked ( $Q$. robur).

During our research, three above-mentioned species of oaks, as well as Fraxinus lanceolata Borkh. and F. pennsylvanica Marsh., Carpinus betulus L., Morus alba L. have been found. Pubescent oak - it is a drought-resistant species; its habitat coincides with the upper boundary of the soils of the foothill forest-steppe (250-350 $\mathrm{m}$ a.s.1.). In these conditions, the oak grows at the average annual air temperature $7-10^{\circ}$ and the amount 
precipitation $-350-500 \mathrm{~mm} \mathrm{yr}^{-1}$ [8]. The isolated forest tracts grow at the forest limits and are usually represented by short-trunk oak trees. These are the remains of larger forest tracts that were previously on the forest-steppe, but were destroyed as a result of economic activities. Such small tracts are in the boundary extreme environmental conditions and therefore they are sensitive to any exposures, including the climatic changes.

Data used. Palaeosol studies of the kurgan Ak-Kaya 9 (second half $4^{\text {th }}$ centuries BC) revealed the peculiarities of the ancient soil, which was moved to raise the mound in the form of horizon A slabs, as well as of undisturbed profiles of the buried soils, the upper horizons of which reflect the bioclimatic conditions of the antiquity. Inside the kurgan Ak-Kaya 9, above the main stone crypt there was made 2325-2350 years ago a wooden ceiling from the logs of young oaks. This allowed obtaining a series of cores from the uniquely preserved timber for dendrochronological studies.

We obtained 38 cores of the nearby forests (12 sites), mainly of the oak (three species) with an average age of 56 years (from 22 to 97). But since the samples of living wood, which had the highest rates of comparability with samples from the kurgan, were representatives of the pubescent oak species, it was these cores that were used for further analysis. Due to differences in climatic responses of individual species of trees, in addition to the oak, a complete saw cut of the Crimean pine (Pinus pallasiana) 116 years old was used. This tree grew in the glade of the Botanical Garden of the Crimean University from 1894 to 2009. The data of the Simferopol meteorological station with a continuous series of observations of the temperature and precipitation since 1886 were used to analyze the interannual variability of the meteorological elements.

Methods. The cores were obtained in IV-IX 2016 from the trunks of living trees using a Pressler borer (Haglöf $400 \mathrm{~mm}$ ). Measurements of the width of annual growth rings were carried out on a high-precision device LINTAB-6 (with precision $1 \cdot 10^{-3} \mathrm{~mm}$ ) for measuring annual growth rings complete with a platform TSAP-Win ${ }^{\mathrm{TM}}$ (Professional 4.0). With its help, the resulting average chronology Half-chrono was constructed according to individual chronologies for each researched area. The results of cross-dating are the compatibility indicators of individual chronologies (the sum of intervals of equal gradient (GLK); cross-correlation (CC); compatibility level (GSL)). The series of radial growth were converted into series of growth indexes (late and early wood) to eliminate edaphic and age effects.

Concentration of oxides and trace elements within the soils were determined by the method of X-ray analysis. The eluviation coefficient $(\mathrm{Ke})$ were determined by the formula: $\mathrm{Ke}=\mathrm{Si} /(\mathrm{Ca}+\mathrm{Mg}+\mathrm{K}+\mathrm{Na})$. When we introduced to the author's formula to calculate the energy costs of soil formation $-\mathrm{Q}$ value [9], the multipliers converting the radiation balance values into the international system of unit measurement, the calculation formula for $\mathrm{Q}$ value $\left(\mathrm{MJ} /\left(\mathrm{m}^{2} \cdot \mathrm{yr}^{-1}\right)\right)$ has been modified into the form: 


$$
Q=B \cdot \exp \left(1.23 \frac{B^{0.73}}{P}\right)
$$

where $\mathrm{B}$ is the radiation balance, $\mathrm{MJ} /\left(\mathrm{m}^{2} \cdot\right.$ year $), \mathrm{P}$ is the annual precipitations, $\mathrm{mm}$.

The highest rate of change under the influence of climate in the temperature and humidity regimes, biotic parameters, etc. [10]. The coefficient Q characterizes the conditions of the entire calendar year and therefore its application for analyzing the climate contribution into the wood growth is more correct than application of other indicators.

Reconstruction of the climate for the ancient period was carried out by using complementary statistical methods of comparing, converting and time series analyzing radial growth by the cores from buried trees with the cores that were obtained in the nearby forests. The conversion of the initial series into a stationary process by the logarithmmation of the original data and by the removal of the trends was carried out to search for the cross correlation of the synchronicity of the formation of the radial growth. This made it possible to identify the low-frequency components in the dendrochronological data by means of a trigonometric function Fourier series of the type:

$$
y=a_{0}+\sum_{i=1}^{n} a_{i} \cos (n w x)+b_{i} \sin (n w x),
$$

where $a_{0}$ models a constant (intercept) term in the data and is associated with the $i=0$ cosine term, $w$ is the fundamental frequency of the signal, $n$ is the number of terms (harmonics) in the series, and $1 \leq n \leq 8$.

Statistical standardization was performed to convert the climatic parameters and radial growth into one dimensionless plane of values. Each value in the time series is standardized: $\mathrm{x}=(\mathrm{x}-\mathrm{M}) / \mathrm{SD}$, where $\mathrm{M}$ and $\mathrm{SD}$ are the overall mean and standard deviation for the untransformed series. With the help of a Wavelet analysis, the main harmonics of processes were discovered, i.e. identified signals that contain numerous nonstationary or transitory characteristics: drift, trends, abrupt changes, and beginnings and ends of events. The reconstruction of the main harmonics of climate changes in the antiquity was carried out on the basis of the system of formulas of the linear cross-correlation with the dendrochronology data. Data analysis and modelling was performed using Time series analysis, Curve Fitting Toolbox and Wavelet Toolbox in the Statistica Advanced + QC for Windows v.10 and MathWorks MATLAB 7.9 R2009b.

\section{RESULTS AND DISCUSSION}

Our analysis showed that under piedmont forest-steppe conditions, the growth of annual rings (PR) reflects the integrated effect of the warmth and moisture in the multi-year regime, since the dependence of the value PR separately from the average annual values of the air temperature and precipitation is weak. At the same time, PR over the years, it reacts more to moisture availability (the coefficient of correlation (r) with the sum of 
precipitation amounted to 0.48 ). The correlation with the temperatures over the year is weak. In this regard, it is advisable to use complex indicators that would take into account the provision of the territory, both with warmth and with moisture. The studies have shown that there is a close correlation $(r=0.51)$ between the index PR and the coefficient of bioclimatic potential Q (by [9]). This coefficient most fully characterizes the peculiarities of growth and development of the wood vegetation throughout the year in the multi-year regime.

In the piedmont forest-steppe, the total annual precipitation is distributed between the warm and cold periods in the proportion 61:39\%. Previously [11], it was shown that the variability of $\mathrm{PR}$ in the coniferous trees in the conditions of Siberia is especially pronounced due to the temperature of the summer period. However, for the piedmont forest-steppe conditions, the total PR of the pine tree has a closer correlation not with PR of the early wood but with PR of the late wood. The dependence of the radial growth of the late wood (PR-L, mm) on the total annual growth (PR, mm) in the pine tree has the form: $\quad P R-L=3.03 \sin (0.13 P R+0.018) ; r=0.87$. This opens up opportunities for analyzing the intra-annual differences in the bioclimatic conditions. Such analysis will be particularly effective for medium and favourable (in terms of the climate) years, when the growth $>2-2.5 \mathrm{~mm} \mathrm{yr}^{-1}$.

Dendrochronological studies in the Belogorsk region (series 16-9) included core samples of the buried wood and the modern analogues of modern oak trees of the nearby forests (12 sites). The samples of the wood from the kurgan (F-1-1 (49 years) and F-1-2 (40 years)) have high compatibility indicators with Half-chrono and therefore they are suitable for creating a generalized chronology of fossil wood. The comparison of TSAPWin growth of the living wood and the fossil wood allowed to determine high comparability rates F-1-2 with F-6-3 (oak pubescent, 32 years, at the northern edge of the continuous forest area). We performed the dendroclimatic reconstructions of the conditions of antiquity by comparing the data of the modern $\mathrm{R}(\mathrm{F}-6-3)$ and ancient $\mathrm{R}(\mathrm{F}-1-$ 2) dendrochronological cross sections.

The original dendro data have certain trends in the growth of trees (Figure 1a), so the growth process was reduced using a logarithmic conversion to a stationary type (Figure 1b). This provided an opportunity to identify low-frequency harmonics of changes in the increment growth of trees of the modern and ancient periods, which are described by the Fourier time function of the form:

for $\mathrm{R}(\mathrm{F}-6-3): R_{C(L n-T)}=0.50 \cos (0.35 t)-0.125 \sin (0.35 t)+0.0806$;

for $\mathrm{R}(\mathrm{F}-1-2): R_{C(L n-T)}=0.21 \cos (0.36 t)-0.012 \sin (0.36 t)-0.003$. 


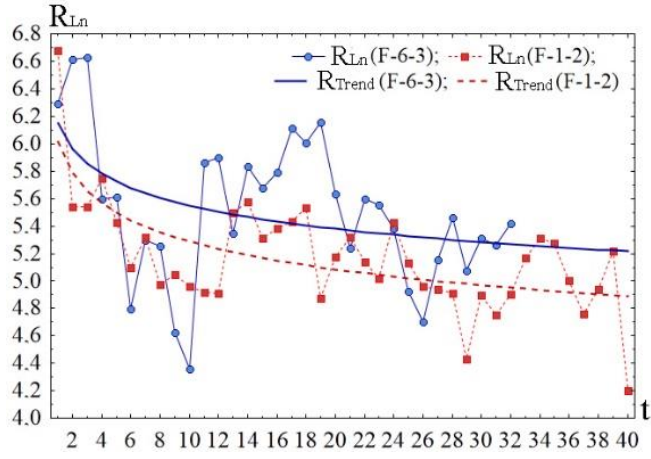

a)

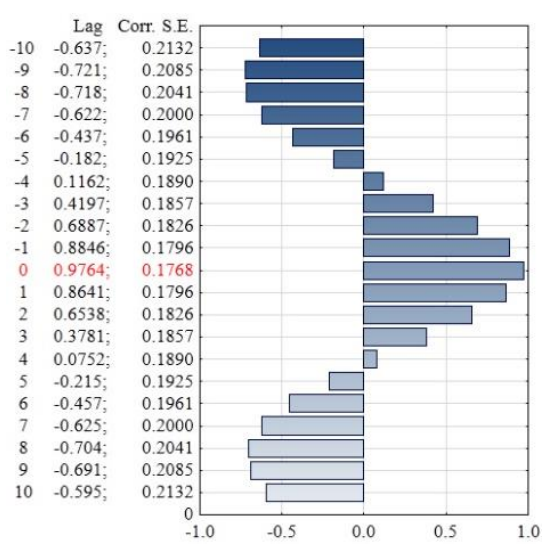

c)

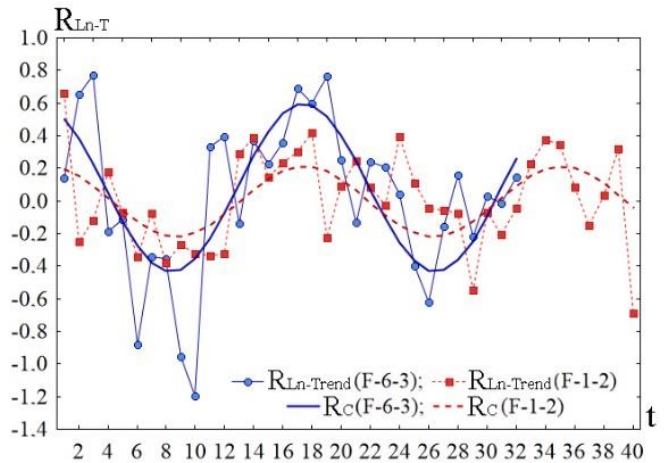

b)

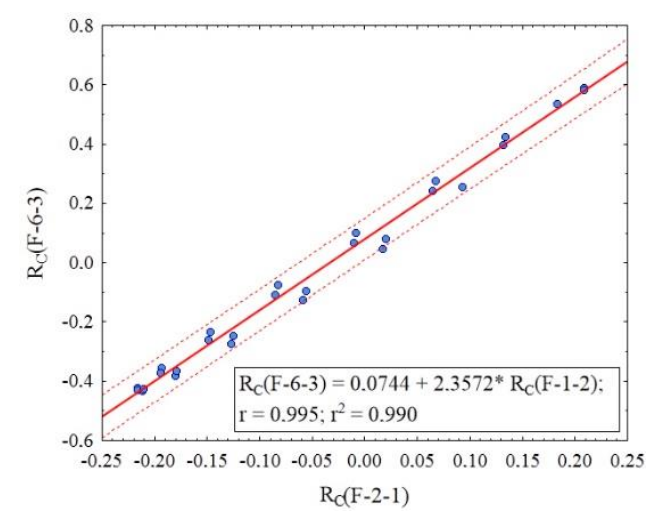

d)

Figure 1. The results of finding the synchronism in the radial growth of oak $(\mathrm{R})$ between the cores of the modern (F-6-3) and antique wood (F-1-2): a) the logarithm $\left(\mathrm{R}_{\mathrm{Ln}}\right)$ and trend $\left(\mathrm{R}_{\mathrm{T}}\right)$; b) the time series and low-frequency cyclic components $\left(R_{C}\right)$ converted to a stationary process $\left(R_{\mathrm{Ln}-\mathrm{T}}\right)$; $\left.c\right)$ cross correlation $\mathrm{R}_{\mathrm{C}}$; ) regression equation between sample cores.

The cross correlation of the low-frequency harmonics was $r=0.98$ (Figure 1c), which makes it possible to estimate the degree of synchronicity of the dynamic correlation as a high one (Figure 1d). The obtained result makes it possible to reconstruct the climate in the ancient period with the help of the identified correlation of the dendrochronological series. The study of the synchronism of the dynamics and the influence of the energy of the climate (Q) on the radial increase in the period 1985-2016 (by R(F-6-3)) was carried out.

For this purpose, the temporal series $\mathrm{Q}$ and tree rings were reduced to a stationary process by a statistical normalization of the initial data and the removal of trends (Figure 2a). Statistical criteria for rationing Q: average is $953.2 \mathrm{MJ} /\left(\mathrm{m}^{2} \mathrm{yr}^{-1}\right)$, the standard deviation is $358.1 \mathrm{MJ} /\left(\mathrm{m}^{2} \mathrm{yr}^{-1}\right)$; for tree rings: average is $285.9 \mathrm{~mm}$, the standard deviation is $164.3 \mathrm{~mm}$.

The fundamental harmonics $\mathrm{Q}_{\mathrm{C}(\mathrm{SN}-\mathrm{T})}$ и $\mathrm{R}_{\mathrm{C}(\mathrm{SN}-\mathrm{T})}$ were determined using an Wavelet analysis by the decomposition of the time series up to the second level. As a result, it was found that the maximum value of cross correlation of the fundamental harmonics ( $r=0.73$ ) is achieved with a time lag $\mathrm{Q}_{\mathrm{R}+1}$, the correlation has a linear form: $R_{C(S N-T)}=-0.20+1.16 Q_{C(S N-T)}$. Then, the statistical normalization, removal of the 
trend and Wavelet analysis for the tree-ring chronology of the buried wood R(F-1-2) were done: average is $192.3 \mathrm{~mm}$, the standard deviation is $111.4 \mathrm{~mm}$, trend: $\mathrm{y}=-0.776$ $\ln (t)+2.1401, r=0.68$. The reconstruction of the basic harmonics of the climate energy in the ancient period ( $\mathrm{QaC}$ ) (Figure 2c) was carried out on the basis of the system of the above-identified relationships "R(F-6-3):R(F-1-2)" and " $\left.\mathrm{R}_{\mathrm{C}(\mathrm{SN}-\mathrm{T})}(\mathrm{F}-6-3): \mathrm{Q}_{\mathrm{C}(\mathrm{SN}-\mathrm{T})}\right)$ " and may be described in the form: $Q a_{C}=\left(2.3572 R_{C(F-1-2)}+0.2744\right) / 1.16$.

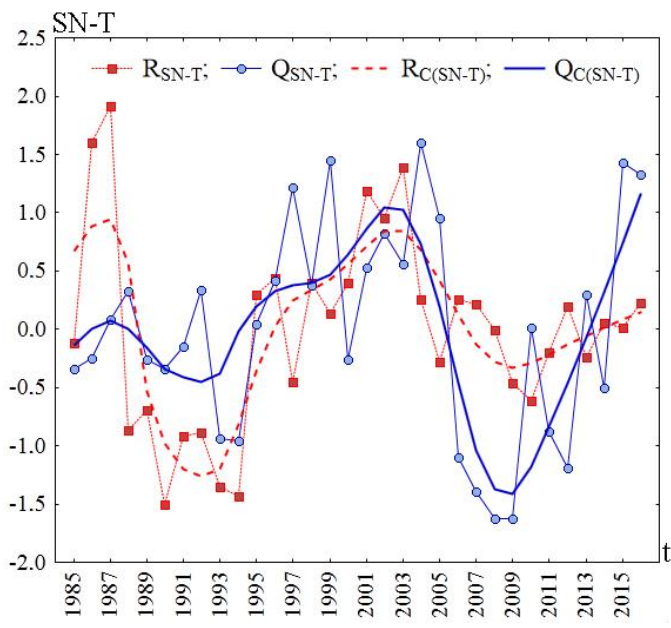

a)

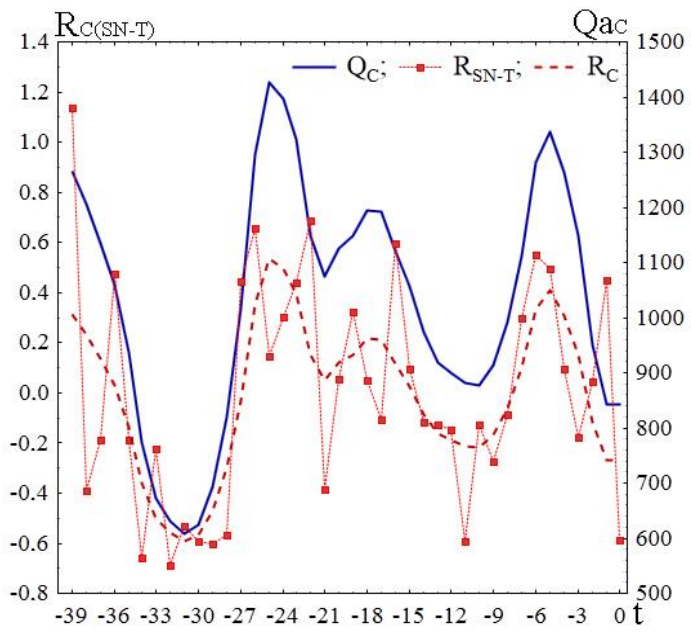

b)

Figure 2. Dendroclimatic reconstructions of the conditions of the antique era: a) synchronism of the dynamics of the normalized series $\mathrm{Q}_{\mathrm{SN}-\mathrm{T}}$ and $\mathrm{R}_{\mathrm{SN}-\mathrm{T}}$ and their cyclic components; $b$ ) the reconstruction of the basic harmonics $\left(\mathrm{Qa}_{\mathrm{C}}\right)$ of the climate energy $\left(\mathrm{R}_{\mathrm{SN}-\mathrm{T}}\right)$ and of the fundamental harmonics of the core samples $\left(\mathrm{R}_{\mathrm{C}}\right)$.

In the Q series for 1987-2016, as a result of cross-correlation analysis with a time shift $\mathrm{Qa}_{\mathrm{C}}$, it was determined that the reconstruction results have the best similarity $(\mathrm{r}=0.54)$ to the chronozone of the instrumental period 1922-1961. In the regional stands of $P$. Sylvestris, a cyclical repetition of minima and deep minima for annual and late wood radial increment were identified and deep minima in the tree ring growth are detected with a frequency close to the Bruckner cycle (34 years) [12].

Thus, the tree-ring chronology established a modern analogue period (1922-1961) for the antiquity, which made it possible to identify the climatic peculiarities in the piedmont forest-steppe within from 2285 to 2310 years ago (Table 2). The climate at that time can be characterized as follows: the average annual air temperature is $10.2 \pm 0.1^{\circ} \mathrm{C}$, the precipitation sum is $457 \pm 19 \mathrm{~mm} \mathrm{yr}^{-1}$, the energy cost for soil formation $(\mathrm{Q}$, according to [9]) is $1030 \pm 35 \mathrm{MJ} /\left(\mathrm{m}^{2} \cdot \mathrm{yr}^{-1}\right)$ (the value $\mathrm{V}$ is $21.5 \%$ ). It was determined that the time necessary for the formation of oak-broad-leaved forests is calculated as 100-500 years [12]. Thus, the medium-term interdecadal variations of the climate in the piedmont foreststeppe up to the middle $4^{\text {th }}$ centuries BC determined its difference from the modern era in a greater degree of moistening (by 4\%) with a certain decrease in the supply of warmth 
and a higher (by 6\%) potential for soil formation. This generally contributed to better conditions for the growth of the piedmont oak forest, but the forests were already in permanent use.

Recently recovered palaeoenvironmental data [13] suggest that around $3 \mathrm{ka} \mathrm{BP}$, new hot and moist climatic conditions correspond already to rendzinas and chernozems rather than the cinnamonic soils of the preceding period. When studying the correlation of the soil formation rates with the solar activity (SA) for the last 5 ka years [6] only one discrepancy was identified: it is the Greek minimum SA (2350 years ago), which was connected with a decrease, although not very significant, in the soil formation rate (extremum is 2150 years ago). During the following centuries, the climate seems to have become more humid. A generalization of the regional palaeogeographic data [14] showed that in the second half of $4^{\text {th }}$ centuries BC the vegetation cover in the modern steppe zone was more diverse and had the appearance of the forest-steppe up to the Roman times.

The soils under the kurgan mound $\left(4^{\text {th }}\right.$ c. BC) - their morphology and properties (pedomemory) show that they are Luvisols on carbonate rocks. The increase in the proportion of silica, the amount of which in the accumulative horizon of the full-Holocene soils varies from $51 \%$ (under steppe) to $54 \%$ (under forest), is particularly indicative. With age, the accumulation in soil $\mathrm{SiO}_{2}$ accelerate but metal sesquioxides decreases. Therefore, the eluviation coefficient $(\mathrm{Ke})$ value should increase if the climate becomes more humid and the soils dry out less, which is observed under the canopy of the forest. The modern soil (horizon A, 0-19 cm) under the steppe vegetation has the value $\mathrm{Ke}$ is 1.0 and the forest buried soil (A, 0-14 cm), which has a brown colour (10YR 5/3) Ke is 1.1 while the darker (dark grey (10YR 4/1 and 3/1)) soil slabs in the kurgan mound are even more leached $-\mathrm{Ke}=3.7-5.9$. This convincingly testifies that the climate up to $4^{\text {th }} \mathrm{c}$. BC was distinguished by higher humidification than in the subsequent period, including the current stage of the formation of the natural environment.

\section{CONCLUSIONS}

For piedmont forest-steppe conditions, a close correlation of the radial growth index and the moisture supply conditions has been identified. The most promising indicator for studying the dynamics of wood growth in the conditions of the Crimean piedmont is the indicator of the climatic energy expenditure on the soil formation. The possibilities of the approach, which unites two types of palaeoecological archives (the chronology of living and fossilized wood for modelling high-frequency changes) and the memory of the buried soils to determine the effects of centuries-old cycles (100-500 years) have been shown when reconstructing the climatic conditions. The assessment of the peculiarities of the climate up to $4^{\text {th }} \mathrm{c}$. BC showed that more favourable conditions for the growth of forests in the piedmont forest-steppe, in which the forest soils were formed (they were preserved under the kurgans), were not significantly different from the present time conditions. This allows suggesting that the isolated nature of the modern forests (as relicts of the oak 
groves more widespread here in the ancient times) is not related to the climate aridization in the last 2300 years, but to the influence of anthropogenic factor (cutting, grazing, etc.).

\section{ACKNOWLEDGEMENTS}

This study was supported by the Ministry of Science and Education of the Russian Federation (the 2017-2019 state assignment for the Belgorod State National Research University, project No. 5.4711.2017/VU).

\section{REFERENCES}

[1] Dunaev, A.V., Dunaeva, E.N., Kalugina, S.V. Forest and People: Human-induced loss of positional resistance of oak forests of forest-steppe. Belgorod State University Scientific Bulletin. Natural sciences, 27(10), pp 34-42, 2014.

[2] Leonelli, G., Coppola, A., Baroni, C., Salvatore, M. C., Maugeri, M., Brunetti, M., Pelfini, M. Multispecies dendroclimatic reconstructions of summer temperature in the European Alps enhanced by trees highly sensitive to temperature. Climatic Change, 137(1-2), pp 275-291, 2016.

[3] Wang, Y., Feng, Q., Kang, X. Tree-ring-based reconstruction of temperature variability (1445-2011) for the upper reaches of the Heihe River Basin, Northwest China. Journal of Arid Land, 8(1), pp 60-76, 2016.

[4] Büntgen, U., Raible, C.C., Frank, D., Helama, S., Cunningham, L., Hofer, D., ... \& Esper, J. Causes and consequences of past and projected Scandinavian summer temperatures, 500-2100 AD. PLoS One, 6(9), e25133, 2011.

[5] Lisetskii, F.N., Goleusov, P.V., Moysiyenko I.I., Sudnik-Wojcikowska B. Microzonal distribution of soils and plants along the catenas of mound structures. Contemp. Probl. Ecol. 7(3), pp 282-293, 2014.

[6] Ivanov, I.V. Lisetskii, F.N. Manycentury periodicity of solar-activity and soil formation. Biofizika, 40(4), pp 905-910, 1995.

[7] Batukaev, A.M.A., Endovitsky, A.P., Andreev, A.G., Kalinichenko, V.P., Minkina, T. M., Dikaev, Z. S. ... \& Sushkova, S.N. Ion association in water solution of soil and vadose zone of chestnut saline solonetz as a driver of terrestrial carbon sink. Solid Earth, 7(2), pp 415-423, 2016.

[8] Kočkin, M.A. Počvy, lesa i klimat Gornogo Kryma i puti ich racional'nogo ispol'zovanija (Naučnye trudy Nikitskogo Botaničeskogo Sada, 38). Kolos: Moscow, 1967, 368 pp. (in Russian).

[9] Volobuev, V.R. Ecology of soils. Israel Program for Scientific Trans. 259, 1964.

[10] Kudeyarov, V.N., Demkin, V.A., Gilichinskii, D.A., Goryachkin, S.V., Rozhkov, V.A. Global climate changes and the soil cover. Eur. Soil Sci., 42(9), pp 953-966, 2009. 
[11] Bryukhanova, M.V., Vaganov, E.A., Wirth, C. Influence of climatic factors and reserve assimilates on the radial growth and carbon isotope composition in tree rings of deciduous and coniferous species. Contemp. Probl. Ecol., 4(2), pp 126-132, 2011.

[12] Matveev, S.M., Chendev, Yu.G., Lupo, A.R., Hubbart, J.A., Timashchuk, D.A. Climatic changes in the East-European forest-steppe and effects on Scots pine productivity. Pure and Applied Geophysics, 174(1), pp 427-443, 2017.

[13] Cordova, C. Crimea and the Black Sea. An environmental history. London - New York: I. B. Tauris, 2016, 235 pp.

[14] Stolba, V.F. La vie rural en Crimée antique: Panskoe et ses environs. Études de Lettres, 1-2, pp 311-364, 2012. 